\title{
Targeting the Strategies of a Bid Sniper
}

\author{
Jarrod Trevathan, Wayne Read, Yong Jin Lee and Ian Atkinson \\ eResearch Centre \\ James Cook University \\ Email:eResearch@jcu.edu.au
}

\begin{abstract}
Bid sniping is a dubious practice used in online auctions whereby a bidder makes a bid in the closing moments in an attempt to deny other bidders time to react. The primary goal for a bid sniper is to win the auction for the lowest price possible, without the risk of being forced into submitting any higher bids if there is competition for the item. This paper investigates the phenomenon of bid sniping and its prevalence in commercial online auctions. We seek to show the extent of bid sniping, understand the rationale of why it occurs, what effect this has on the other auction participants, and what can be done to prevent the practice. Based on this understanding, we present a software bidding agent that follows a bid sniping strategy. The agent has the ability to suppress an auction's price through knowing when to bid, how much to bid, how to deal with rivals, and when to cease bidding. We also propose a new online auction format that can eliminate/reduce the effect of bid sniping. The proposal adds an undisclosed random time-out extension to an auction's finishing time to entice bidders to bid their maximum amount immediately or risk being excluded from the auction.
\end{abstract}

Keywords: Online auctions, e-commerce, software bidding agents, fraud, shill bidding

\section{INTRODUCTION}

Online auctions are a highly successful mechanism to exchange items from the comfort of one's own home. However, the move towards an automated marketplace has resulted in changes to the auctioning structure that have many undesirable consequences. The majority of online auctions terminate at a preset expiration time. This format allows bidders to engage in a dubious bidding practice referred to as bid sniping.

Bid sniping is where a bidder submits a bid in the closing moments of an auction (see [1], [6], [12], [13]). The goal is to deny other bidders time to react. The bid sniper hopes that his/her bid will win the auction for the minimal amount needed. This is in contrast to regular bidders that bid competitively throughout the auction. By deferring bidding until the auction's end, the bid sniper will minimise the risk of being outbid and having to engage in a rally with other bidders, which inevitably pushes the price upwards.

While bid sniping isn't illegal, its use is discouraged by the major online auction vendors. Instead, eBay ${ }^{1}$ recommends that a bidder should only place a single bid at his/her maximum valuation using the proxy bidding system [3]. Despite this recommendation, bid sniping is rampant, and is now considered as a natural part of the online auctioning experience. In fact, economists and business analysts advise that bid sniping is the best and most common strategy to use (see [9], [12], [15]).

\footnotetext{
${ }^{1}$ www.ebay.com
}

Essentially, bid sniping denies a seller revenue that might have otherwise been obtained through a competitive bidding process. It also frustrates other bidders who find that they have only lost during the closing seconds to a minimal bid - which they might otherwise have attempted to outbid. The situation is so common that most auctions now have degraded into a competition between snipers during the closing seconds. In general, only a novice or naive bidder bids early as s/he will have to pay more for the item, and it also exposes him/her to certain types of fraud (explained later).

To further complicate matters, some bidders have resorted to using software bidding agents to gain a competitive advantage. A software bidding agent is a program that bids on a human bidder's behalf (see [2], [4], [10], [13]). In the ideal (and intended) sense, the user enters a maximum s/he is willing to pay. The agent will incrementally outbid competitors up to the maximum price. This saves the human the effort of constantly having to monitor an auction for bidding activity (as some auctions can last for days). eBay's proxy bidding system is an example of such a bidding agent. However, there are commercial bidding agents that now offer bid sniping services.

A bid sniping agent is an automated program that monitors an auction and then submits a bid during the closing moments. Bid sniping agents give their owners an advantage over ordinary bid snipers. Firstly, the human doesn't have to monitor the auction, and secondly the reaction time can be down to fractions of a second from the closing time. As a result, it is humanly impossible to compete unless everyone begins to employ bid sniping agents. This then raises serious questions over the effectiveness of online auctions as an exchange mechanism given the prominence of bid sniping.

This paper investigates the phenomenon of bid sniping and its prevalence in commercial online auctions. We seek to show the extent of bid sniping, understand the rationale of why it occurs, what effect this has on the other auction participants, and what can be done to prevent the practice. Based on this understanding, we present a software bidding agent that follows a bid sniping strategy. The agent has the ability to suppress an auction's price through knowing when to bid, how much to bid, how to deal with rivals, and when to cease bidding. We also propose a new online auction format that can eliminate/reduce the effect of bid sniping.

This paper is organised as follows: Section II describes general bid sniping behaviour, existing commercial bid sniping agent products, and how bid sniping is related to other undesirable bidding practices. Section III presents an analysis 
of the prevalence of bid sniping in commercial online auctions. Section IV introduces a model for a software bidding agent that follows a bid sniping strategy. Section V discusses methods to counteract the use of bid sniping. Section VI provides some concluding remarks and avenues for future work.

\section{BID SNIPING}

This section provides insight into a bid sniper's strategy, and how a commercial bid sniping agent operates. It presents a brief comparison of bid sniping to another undesirable bidding practice referred to as shill bidding.

\section{A. A Bid Sniper's Strategy}

By studying eBay auctions where sniping had occurred, results from the literature, and through practical experience at sniping ourselves, we determined the core strategies for being a successful sniper in an online auction. The following outlines the major strategy/goals a bid sniper will follow:

1) Win the auction: The sniper is in the game to win, and will bid accordingly to ensure that this happens.

2) Only pay the minimal price subject to a valuation: While a sniper's main goal is to win, s/he will not do this at any cost. In reality the sniper is only prepared to pay an amount up to a set valuation. If the sniper does happen to be outbid, s/he will only bid up to this valuation within the constraints of the time remaining in the auction.

3) Submit as few bids as possible: A sniper only wants to submit one, or in the worst case, a few bids. The more bids that are submitted, the higher the auction price will be. In general, the sniper will only submit as many bids as are necessary up to the target valuation. The availability of the item or the existence of auctions with similar items could also influence the sniper's decision to submit bids. If the sniper is being forced to submit more bids, s/he may simply give up and focus on another auction for the same item where the price is lower.

4) Has a preference towards auctions with a lower bid volume: A high bid volume suggests that there is a significant amount of competition for an item. In general, the more bids that have been submitted in an auction, the higher the price will be. A sniper will be reluctant to participate in an auction with a high bid volume, and will instead opt for an auction with a low bid volume and price. It is in such an auction that the sniper will be most likely to "steal" the item for the minimal price.

5) Avoid bidding rallies: Bidding rallies occur when two or more bidders aggressively outbid each other in an attempt to win. A sniper will avoid bidding rallies as this is a logical extension of behaviours 3 and 4 above.

6) Avoid large proxy bids: Timing is of the upmost importance to a sniper. The sniper must place a bid that is large enough to get ahead, but allows the possibility of submitting further bids if the initial bid is not large enough to get in front of a competitor's proxy bid. However, the bid must not be too large so that competing late bidders force the bid up to its maximum. Therefore, a series of smaller proxy bids is a safer option provided that these can be submitted prior to the auction's end.

A sniper is considered to have been successful if s/he has won the auction for a price less than or equal to his/her true valuation. The sniper is considered to have been unsuccessful if s/he has not won the auction as s/he was outbid and was unable to enter a competing bid on time, or s/he was outbid and the competing bid is higher than his/her true valuation. The first instance is more of a frustration to the sniper, whereas the second scenario is an outright loss. A sniper can also be considered as having been unsuccessful if $\mathrm{s} / \mathrm{he}$ has won the auction, but was forced to pay more than his/her true valuation.

The sniper's main source of competition includes proxy bids and other snipers. As a sniper is bidding close to the auction's end, if s/he runs up against a proxy bid for more than the bid s/he has submitted, then s/he must submit a new higher bid in order to win. The sniper has two possible strategies in this situation. Firstly, s/he can keep submitting new bids in an incremental manner until s/he outbids the proxy bid. However, this approach is contingent on the amount of time remaining in the auction. The sniper might actually run out of time before s/he has outbid the proxy bid. Alternately, the sniper might submit a proxy bid for an amount up to his/her true valuation. If this is greater than the rival proxy bid, then $\mathrm{s}$ /he will win. However, in doing so the sniper has revealed his/her true valuation, and runs the risk of other late bidders competing with him/her thereby raising the price.

Competing snipers are the second main cause of concern for a bid sniper. It is common for several snipers to enter competing bids during the closing seconds. This will force a bid sniper to have to enter several bids quickly in order to remain ahead. This is undesirable for a sniper as the price is run up, and bidding becomes more erratic potentially leading to errors such as bidding more than the true valuation.

\section{B. Existing Bid Sniping Programs/Vendors}

A bid sniping agent is a software bidding agent that follows a late bidding strategy. The sniping agent constantly monitors an auction, and waits until the last moment to bid. Companies such as Bidnapper.com ${ }^{2}$, ezsniper ${ }^{3}$ and Auction Sniper ${ }^{4}$ now offer sniping services for eBay auctions. These companies actively promote the sniping strategy, touting that "everybody does it" and it is the optimal strategy to "win more auctions". They point to literature to back their position (e.g., [9], [15]).

A bidder either subscribes for a fee, or pays on a per use basis for each auction. It is not necessary for a customer to download proprietary software, nor is s/he obligated to be permanently connected to the Internet. Instead, the customer provides the sniping service with account credentials (i.e., user name/password), a list of auctions, and the maximum price $\mathrm{s} / \mathrm{he}$ is willing to pay for each respective item. The sniping service hosts dedicated servers that continually monitor online auctions and place sniping bids directly with the auctioneer.

\footnotetext{
${ }^{2}$ http://www.bidnapper.com

${ }^{3}$ http://www.ezsniper.com

${ }^{4}$ http://www.auctionsniper.com
} 
As the sniping service is not actually part of the auctioneer, it must periodically poll the auctioneer's servers for accurate information. The speed at which the sniping service can react is limited by the physical connection to the auction server, and therefore it is susceptible to network delays. Bidnapper has gone to the extreme lengths of placing local servers in the same countries/regions as the auctioneer's servers to minimise the effect of network delays. The resources and dedication of such sniping services is a testament to their profitability.

While bid sniping services are convenient, one must raise questions such as:

- Is bid sniping ethical? (See Marcoux [7].)

- Is bid sniping something commercial companies should be condoning and profiting from?

- If online auctioneers discourage its use, why don't they pursue perpetrators or try to prevent the activity?

- Users of bid sniping services should also consider whether they are comfortable with providing their personal account credentials:

- Are credentials being stored/transmitted securely?

- What is preventing them from being misused?

- What if two bidders request to snipe the same auction?

- Does the sniping service vendor take money from both of them knowing full well the bidder with the higher valuation will win?

- Does the sniping service operate in a consistent manner each time, or does a human make an opinionated judgement to influence its operations?

- Is it fair to employ the services of several sniping agents on a particular auction to almost guarantee victory?

- Are there any other types of undesirable behaviour that arise from, or are used in conjunction with bid sniping?

\section{Comparing Bid Sniping with Shill Bidding}

Shill bidding (or shilling) is the act of introducing fake bids into an auction on the seller's behalf to artificially inflate the price of an item (see [3], [5], [6], [8], [11], [12], [13], [14]). Bidders who engage in shilling are referred to as shills. To win the item, a legitimate bidder must outbid a shill's price. If one of the shills accidentally wins, then the item is re-sold in a subsequent auction. Shill bidding is a problem as it forces legitimate bidders to pay significantly more for the item.

To be effective, a shill must comply with a particular strategy which attempts to maximise the pay-off for the seller (i.e., the difference between the final price and the uninflated price). A shill's goal is to lose each auction. A shill has a seemingly infinite budget. If the shill wins, the item will have to be re-auctioned. Resale of each item costs the seller money and effort, thereby eroding the possible gains from shilling.

The shill faces a dilemma for each bid they submit. Increasing a bid could marginally increase the revenue for the seller. However, raising the price might also result in failure if it is not outbid before the auction terminates. The shill must decide whether to "take the deal" or attempt to increase the pay-off.

On the contrary, a bidder's goal is to win. A bidder has a finite budget and is after the lowest price possible. Increasing a bid for a legitimate bidder decreases the money saved, but increases the likelihood of winning.

A shill has the following characteristics (as identified by Shah et al [12] and Trevathan and Read [13], [14]):

1) A shill tends to bid exclusively in auctions only held by one particular seller.

2) A shill tends to have a high bid frequency due to running up the final price by outbidding others.

3) A shill has few or no winnings for the auctions participated in.

4) It is advantageous for a shill to bid within a small time period after a legitimate bid to give legitimate bidders as much time as possible to submit a new bid before the closing time of the auction.

5) A shill usually bids the minimum amount required to outbid a legitimate bidder. If the shill bids an amount that is much higher than the current highest bid, it is unlikely that a legitimate bidder will submit any more bids and the shill will win the auction.

6) A shill will tend to bid more closely to the beginning of an auction, as bidding too close to the end could result in an accidental win.

The most extreme shill bidding strategy is referred to as aggressive shilling. An aggressive shill continually outbids everyone thereby driving up the price as much as possible. This strategy often results in the shill entering many bids.

In contrast, a shill might only introduce an initial bid into an auction where there has been no prior bids with the intent to stimulate bidding. This kind of behaviour is a common practice in both traditional and online auctions. However, most people typically do not consider it fraudulent. Nevertheless it is still shilling, as it is an attempt to influence the price by introducing spurious bids. This is referred to as benign shilling in the sense that the shill does not continue to further inflate the price throughout the remainder of the auction. A benign shill will typically make a "one-off" bid at or near the beginning.

Regardless of the strategy employed (i.e., aggressive or benign), a shill will still be a bidder that often trades with a specific seller but has not won any auctions.

Sniping behaviour is the exact opposite of shilling. A sniper's goal is to win the auction for the lowest price. Whereas a shill's goal is not to win and to inflate the price. Bid sniping is probably the most widely recognised defence against shill bidders. A sniper may not be able to prevent shilling occurring during an auction. However, the sniper can prevent itself from being shilled. In fact, the ease at which shilling can occur has largely exacerbated the amount of sniping that occurs.

\section{How PREvalent IS Bid SNiPing?}

This section examines how prevalent bid sniping actually is in commercial online auctions.

Shah et al [12] performed a data mining study into the amount of sniping in 12,000 eBay auctions. A clustering algorithm analysed the bidders' bidding strategies based on the variable bid time, bid price and ask price. Their results showed 


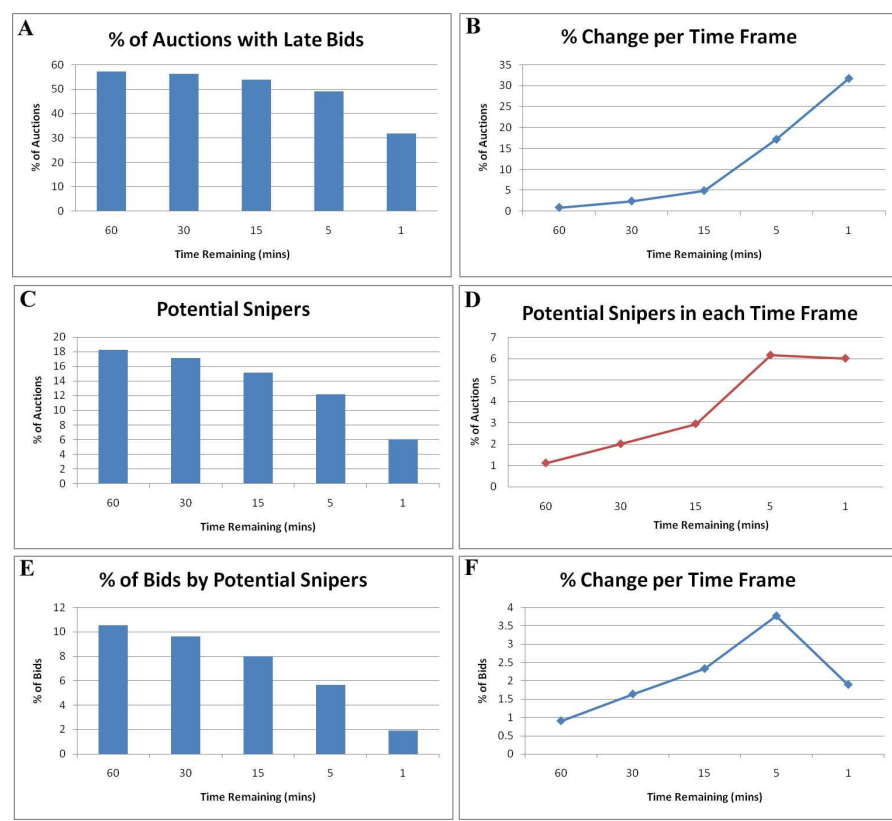

Fig. 1. Statistical analysis of late bidding in 4, 298 eBay auctions

bid sniping (or late bidding) is the most common behaviour among bidders for the majority of auctions.

To confirm the more recent state of affairs in online auctioning, we collected data from 4,298 eBay auctions. The auction data was for three commonly available, desirable electronic items. These were the Nokia N95 $8 G B$ mobile phone, Sony Playstation 3, and Apple iPhone. We started collecting the auction data in 2008/2009 when these items were new and freshly released into the market. These auctions had durations of 1 day, 3 days, 5 days, 7 days and 10 days.

While there is no strict definition for bid sniping, it is generally accepted that it is a bid submitted just prior to the auction close. However, how close to the auction end does a bid have to be submitted to be considered as a sniper bid? For our analysis, we examined 'late bids' submitted over several time frames based on whether they were submitted within 60 , $30,15,5$ and 1 minute(s) of the time remaining.

Figure 1 A shows a percentage of auctions with late bids. This indicates that the following percentages for each time frame respectively are $57.05 \%$ (60 mins), $56.16 \%$ (30 mins), $53.77 \%$ (15 mins), $48.88 \%$ (5 mins) and $31.72 \%$ ( $1 \mathrm{~min}$ ). Results from an earlier time are inclusive of the time frames closer to the auction's close. Figure $1 \mathbf{B}$ shows the percentage change between each time frame respectively is $0.89 \%$ ( 60 - 30 mins), $2.39 \%$ (30 - 15 mins), $4.88 \%$ ( 15 - 5 mins), $17.16 \%$ (5 $-1 \mathrm{~min})$ and $31.72 \%$ ( 1 - $0 \mathrm{~min})$. The most significant increase in the percentage of auctions with late bids occurs during the final 5 minutes. Therefore, almost $60 \%$ of the auctions under study had bids that can be considered as late and nearly $50 \%$ contained potential sniper bids.

Figure $1 \mathbf{C}$ tries to ascertain what percentage of bidders can potentially be considered as bid snipers. Specifically, we concentrated on 'first time bidders' during these periods. That is, the bidders that only commenced bidding within the last hour of the time remaining - no bids had been submitted prior to this. Out of a total of 26,763 bidders, the following percentage of auctions with first time bidders in each respective time frame is $18.25 \%-4,886$ bidders (60 mins), $17.14 \%$ - 4, 589 bidders (30 mins), $15.14 \%$ - 4, 052 bidders ( 15 mins), $12.19 \%-3,263$ bidders (5 mins), and $6.01 \%-1,611$ bidders $(1 \mathrm{~min})$. Figure $1 \mathbf{D}$ shows the percentage change between each time frame respectively is $1.1 \%$ (60 - 30 mins), $2 \%$ (30 - 15 mins), $2.95 \%$ ( 15 - 5 mins), $6.17 \%$ (5 - 1 min) and $6.01 \%(1-0 \mathrm{~min})$. The greatest increase occurs in the last 5 minutes. Therefore, approximately $12 \%$ of the auctions under study contained what could be considered as bid snipers with up to $18.25 \%$ being definitely suspicious late bidders.

Figure $1 \mathbf{E}$ shows the percentage of bids placed by 'late' or potential bid snipers (identified above). The percentage for each respective time frame is $10.54 \%-12,716$ bids ( 60 mins), $9.63 \%$ - 11, 626 bids ( 30 mins), $8 \%$ - 9, 653 bids (15 mins), $5.66 \%-6,840$ bids (5 mins) and $1.89 \%$ - 2, 248 bids ( $1 \mathrm{~min}$ ). Figure $1 \mathbf{F}$ shows the percentage change between each time frame respectively is $0.9 \%$ (60 - 30 mins), $1.63 \%$ (30 - 15 mins), $2.33 \%$ (15 - 5 mins), $3.77 \%$ (5 - $1 \mathrm{~min}$ ) and $1.89 \%$ (1 - $0 \mathrm{~min}$ ). This suggests that the proportion of sniping bids is extremely small compared to the proportion of snipers. In the $1 \mathrm{~min}$ time frame, $6.01 \%$ of the total bidders placed only $1.89 \%$ bids. Therefore, late bidders do not place many bids and the majority of bids are due to early bidders.

In conclusion, the majority of auctions have late bids (in the last 60 mins), a significant proportion of bidders only commence bidding in the final 60 mins and submit very few bids - consistent with a bid sniping strategy.

\section{Bid Sniping Agent Design and Operation}

There is no formal documentation on how a bid sniping agent operates. As a result there is no way to determine exactly how a bid sniping service undertakes its functions. Lack of published documentation raises questions over the consistency of bid sniping services and whether they always act in a manner that is the most beneficial to the customer.

This section presents a specification for an automated bidding agent that engages in a bid sniping strategy. It describes the auction structure, how the bid sniping agent operates, and the rules that govern its behaviour. The purpose for detailing a bid sniping agent is to translate the strategy we outlined in Section II-A into a formal program. If the program was to be used by a bid sniping service, then the customer would be able understand how the bid sniping process operates.

\section{A. Components of an English Auction}

In order to participate in an auction, a bidder must register. $\mathrm{S} / \mathrm{h}$ is provided with a unique bidder id, $b_{i d}$, which is used to submit bids. During the initialisation stage, the auctioneer sets up the auction and advertises it (i.e., item description, starting time, etc.). An auction is given a unique number, $a_{i d}$, for identification purposes. In the bidding stage, a bidder computes his/her bid and submits it to the auctioneer. The 

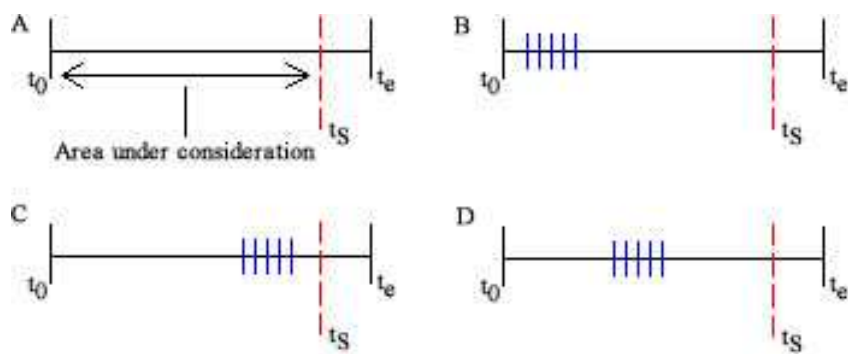

D
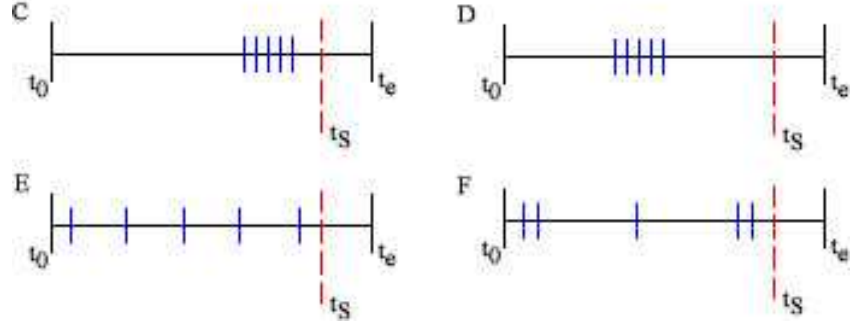

Fig. 2. Different scenarios for how bids can be distributed throughout an auction in progress.

agent can place a bid in auction $a_{i d}$, for price $p^{\prime}$, by invoking the submit bid( $\left.\mathbf{a}_{i d}, \mathbf{p}^{\prime}\right)$ function.

The auctioneer must supply intermediate information to the agent pertinent to the auction's current state. The agent can request a price quote for a particular auction by invoking the obtain price quote $\left(\mathbf{a}_{i d}\right)$ function. This includes the start time $t_{0}$, end time $t_{e}$, and current time $t_{c}$ for the auction (where $t_{0} \leq t_{c} \leq t_{e}$ ), the starting bid (if one exists) and the current price $p$. It is assumed that the agent has access to the entire bid history up to the current time in the auction. The history can be considered as an ordered set $\mathcal{H}=\left\{h_{1}, h_{2}, \ldots, h_{n}\right\}$, $|\mathcal{H}|=n$, that contains price quote triples $h_{i}=\left(t_{j}\right.$, price, $\left.b_{i d}\right)$, where $1 \leq i \leq n . t_{j}$ is the time the bid is submitted where $t_{0} \leq t_{j} \leq t_{e}$. The last element is the latest price quote for the auction (i.e., $h_{n}$ is the current highest bid).

During the winner determination stage, the auctioneer chooses the winner according to the auction rules (e.g., who has the highest bid, whether the reserve has been met, etc.).

\section{B. Bid Sniping Agent Directives}

A bid sniper's core strategy was outlined in Section II-A. The agent's goals are designed to capture this behaviour. Essentially the agent will be programmed to win the auction for the lowest price without exceeding the bidder's valuation. This must be done in a manner whereby the agent uses the fewest number of bids to avoid running up the price. Ideally the sniping agent should operate using a slim time margin that denies other bidders time to react before the auction terminates. We propose a set of directives that a bid sniping agent must adhere to. If these directives are satisfied, the agent submits a bid. Each directive is described in turn.

$D_{1}$ - Give preference to auctions with a low bid volume. If there are two auctions for identical items, then the agent should preferably bid in the one with the least amount of competition so far. A high bid volume suggests an increased likelihood that the agent will run into significant competition.

The ideal situation for a sniper is if no bids have been submitted so far. However, if some bids have been made, then the agent must make a decision about how competitive the auction is. The question is "how many bids make an auction too competitive?".

Figure 2 shows the logic used in the calculation of $D_{1}$. Let $t_{S}$ denote the time after which the agent will only consider bidding in an auction (explained further in directive $D_{2}$ ). Then the agent is able to observe all bids between the period of $t_{0}$ and $t_{S}$ where $t_{0}<t_{S}<t_{e}$. The agent must make its decision based only on the bid volume for this period (Figure $2 \mathbf{A}$ ). The basic approach is as follows:

1) Based on the auction data from Section III, the average number of bids submitted per auction is 30 .

2) If the number of bids submitted so far exceeds this average (minus 11\% - the late bidders from the analysis), then the auction is too competitive and should be avoided in favour of a less competitive auction.

However, this is a rather simplistic approach that does not take into account the dynamics of the bidding trends. A more sophisticated approach is required.

There are several scenarios to consider. Figure $2 \mathbf{B}$ shows how several bids tend to cluster towards the auction's beginning. Figure $2 \mathbf{C}$ gives an opposite example where bids cluster more towards $t_{S}$. Figure $2 \mathbf{D}$ illustrates an example where there is consistent bidding throughout the time elapsed so far.

Example $\mathrm{B}$ appears to be more beneficial for the agent than scenario $\mathrm{C}$. In scenario $\mathrm{C}$ there is significant activity about the time where the agent would commence bidding, and therefore an increased likelihood that such bidding would continue. Whereas scenario B suggests (but doesn't guarantee) that there will be limited activity when the agent commences bidding. Scenario D is somewhere in between, while not very beneficial, it is not overly detrimental either. Scenario E is statistically very close to example B. It is useful to try quantify this information to determine how the bidding is clustered and whether the bid rate is increasing or decreasing over time.

Our approach proceeds as follows: The faster the bids, the shorter the bid time between them. Conversely, the slower the bids the longer there is between them. We need to find out if the inter bid time is increasing or decreasing by differencing the data between successive bid intervals. This will allow characterise an auction in terms of the scenarios from Figure 2.

Let $t_{1}, t_{2}, t_{3}, \ldots, t_{n}$ denote all of the bid times between $t_{0}$ and $t_{S}$. The inter bid time between $t_{i}$ and $t_{i-1}$ is

$$
\Delta t_{i}=t_{i}-t_{i-1}
$$

The time increment between two successive inter bid times is

$$
\Delta^{2} t_{i}=\Delta t_{i}-\Delta t_{i-1}
$$

Note that $\Delta^{2} t_{i}$ is equivalent to the second order derivative. Find the average of the sign (i.e., + or -) to determine whether the bid rate is increasing or decreasing

$$
S_{N}=\frac{1}{N} \sum_{i=1}^{N} \operatorname{sgn}\left(\Delta^{2} t_{i}\right)
$$

where $-1 \leq S_{N} \leq 1$ and

$$
\operatorname{sgn}(x)= \begin{cases}+ & \text { if } x>0 \\ - & \text { if } x<0 \\ 0 & \text { if } x=0\end{cases}
$$


If the result is negative, then the bid rate is increasing. If it is positive, then the bid rate is decreasing. This can be weighted to give preference to bidding behaviour closer to $t_{S}$ as follows

$$
W_{N}=\frac{2}{N(N+1)} \sum_{i=1}^{N} i \operatorname{sgn}\left(\Delta^{2} t_{i}\right)
$$

where $-1 \leq W_{N} \leq 1$.

The user supplies a risk parameter $\mu$, that dictates whether to participate depending on the value of $W_{N}$. When comparing two auctions, preference is given towards an auction which has the greatest (or more positive) value. Note that this metric is only useful when there are more than two bids in the auction so far. The pseudocode for $D_{1}$ is as follows:

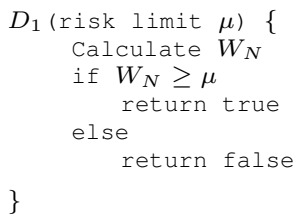

$D_{2}$ - Only bid close to the auction's end. If the sniper bids too early, it risks being outbid, in which case it will have to submit another bid and pay more in order to win. To avoid this, the user supplies the agent with a risk limit, $\theta, 0 \leq \theta \leq 1$. The agent is prohibited from bidding if the auction is not more than $(\theta \times 100) \%$ complete. We refer to this as sniping time threshold, and denote it as $t_{S} . t_{S}$ is the absolute bound before which sniper is prevented from bidding. The auction's duration, $d$, is calculated as $d=t_{e}-t_{0}$. The sniper time threshold, $t_{S}$ is calculated as $t_{S}=\theta d$. The agent can only submit bids when $t_{S} \leq t_{c}$. Smaller values of $\theta$ means that the sniper bids earlier and increases the risk that a sniper might be outbid in an auction. $D_{2}(\theta)$ is a function that takes the risk limit $\theta$, and returns true or false regarding whether the agent is able to bid. The pseudocode for $D_{2}$ is as follows:

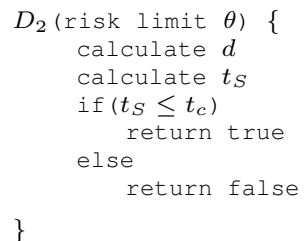

$D_{3}$ - Bid until the target price has been reached (i.e., the bidder's true valuation of the item). $D_{3}(p, \alpha)$ is a function that takes the current price $p$, the sniper's target price $\alpha$, and returns true or false regarding whether the agent should continue to bid. The agent will only bid when the current price $p$, is less than or equal to $\alpha$. The pseudocode for $D_{3}$ is as follows:

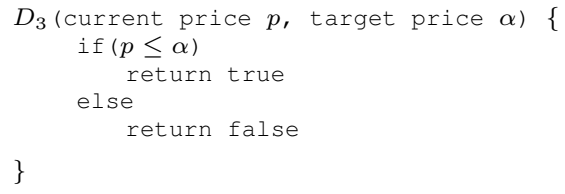

$D_{4}$ - Bid minimum amount required. As part of the price quote, the auctioneer also provides information about the minimum amount required to outbid the highest bid. This is usually calculated as a percentage of the current high bid, or is determined according to a scalable amount depending on the current high bid. $D_{4}(p)$ is a function that takes the current price $p$, and returns the minimum amount the agent should bid. (However, there are some exceptions to this rule as dictated by $D_{7}$.) The pseudocode for $D_{4}$ is as follows:

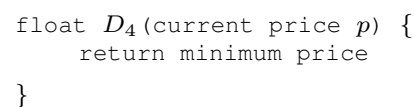

$D_{5}$ - Bid slowly/cautiously after a rival bid. The agent must cautiously consider its actions when a new rival bid is placed after its bid. If the rival bid is not attributed to an automatic proxy bid, then the agent has an active adversary.

Unlike a shill bidder that outbids a rival immediately, a sniper must take a different approach. If the sniper bids too quickly, then it gives the rival time to consider the new bid and increases the likelihood that a new competing bid will be entered. This will force the sniper to enter more bids, ultimately pushing up the price.

While the sniper should delay bidding as long as possible, s/he can't wait too long as the auction will terminate before s/he makes a new bid. The problem is exacerbated when the rival bid is from an earlier proxy bid. In this case, the sniper might need to make several bids to determine the magnitude of the proxy bid. Dealing with proxy bids is the focus of $D_{7}$.

For now, the agent uses some simple logic to determine when to enter a new bid. It determines how much time is remaining in the auction. It then divides this time by two and uses the midpoint as its choice of when to bid next (denoted as $t_{b}$, where $t_{S} \leq t_{b}<t_{e}$ ). If the agent is outbid again, then it repeats the process of dividing the remaining time by two and using the midpoint as its choice of when to bid. For each new rival bid submitted, the process repeats creating successively smaller time units within the auction's remaining time.

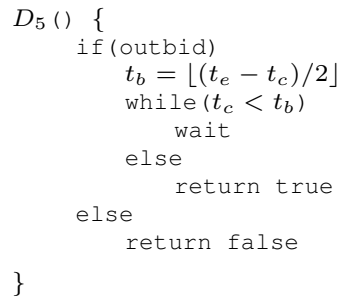

\}

However, a problem with this approach is that it is deterministic. A rival can use this information to deduce exactly when the sniper will bid next. Instead, the agent can randomly select a time between the midpoint of the time remaining and the auction's end. This will make it more difficult for a rival to work out the sniper's exact timing.

$D_{6}$ - Do not engage in bidding rallies if outbid. In the event that the agent is outbid, the user supplies an optional parameter $\Omega$, which indicates how many additional bids can be submitted. Note that the number of additional bids to submit is generally dictated by $D_{3}$, therefore the agent will continue bidding up until the target price $\alpha$ is exceeded. $D_{6}$ provides 

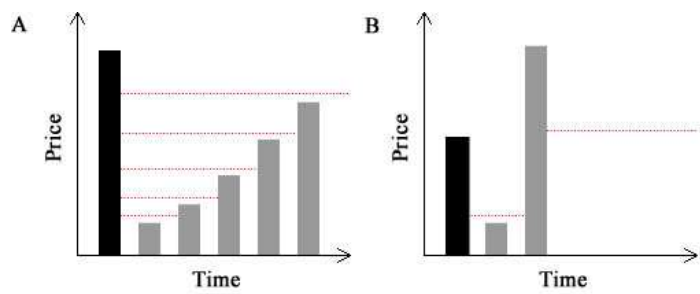

C

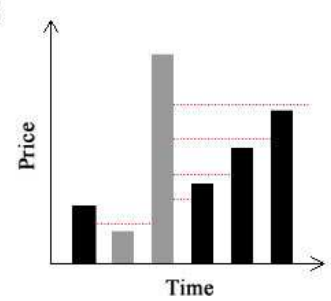

D

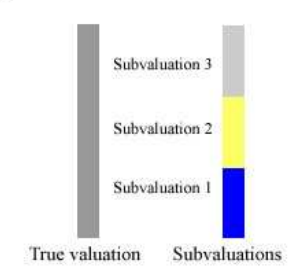

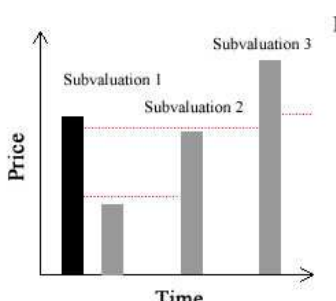

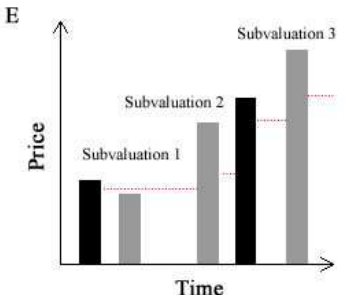

Fig. 3. Different scenarios for dealing with rival proxy bids. A illustrates a thrashing scenario where the agent places many incremental bids to work up to the proxy bid's maximum. B shows a more desirable scenario where the agent works out that this is a proxy bid and then places one large proxy bid of its own. $\mathbf{C}$ depicts the shortcomings of scenario $\mathbf{B}$ whereby a rival forces up the price. $\mathbf{D}$ highlights a better strategy whereby the agent submits subvaluation proxy bids at staggered time intervals. E gives an example of how the strategy shown in $\mathbf{D}$ can thwart rival bids.

a mechanism to override $D_{3}$ such that no further bids will be made regardless of the current price in relation to $\alpha$. If $\Omega$ is set to $\infty$, then $D_{6}$ will allow for any number of bids to be submitted unless otherwise dictated by $D_{3}$. This behaviour is useful when the agent is observing several auctions for identical items. It can force the agent to quit from the current one in favour of participating in a less competitive one. The pseudocode for $D_{6}$ is as follows:

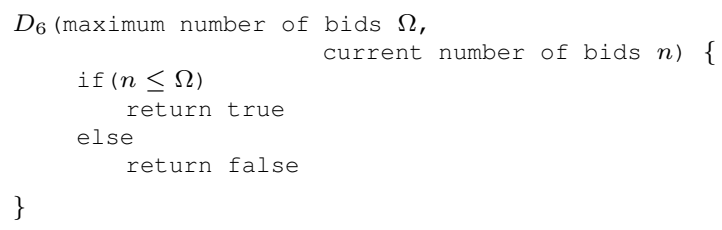

Here $n$ denotes the number of bids the agent has submitted thus far.

$D_{7}$ - Detect presence of proxy bids and bid accordingly. The agent needs to determine if it is up against a proxy bid and whether it can still win for the minimal amount required within the time remaining. In the absence of a proxy bid detection mechanism, the agent will thrash and incrementally bid against the proxy bid (see Figure 3 A). The agent will then either run out of time (i.e., the auction will close), reach its true valuation and cease bidding (i.e., $D_{3}$ ), or exceed the maximum number of bids allowable to prevent a rally (i.e., $D_{6}$ ).

Assuming that there is only one competing proxy bid, once detected, the agent's best strategy may be to submit a final proxy bid for its true valuation. If this value exceeds the rival proxy bid, then the agent will win the auction for the minimal amount required to outbid the contender (see Figure $3 \mathbf{B}$ ). However, if the contender has time to place another bid, it might push the agent's bid towards its true valuation by inadvertently causing a rally which the agent is locked into (i.e., $D_{6}$ can't stop the bidding until the agent's proxy bid has been outbid) (see Figure $3 \mathbf{C}$ ).

Depending on the amount of time remaining, the agent might be able to split its bid up into a series of smaller values (or subvaluations) between the current price and its true valuation. When a proxy bid is detected, the agent can place its own proxy bid with a maximum price at the first subvaluation. If this exceeds the rival bid and there are no other contending bids placed in time, then the agent will win the auction for the minimal amount required to outbid the contender (see Figure 3 D). However, in the aforementioned circumstance where another rival bid is placed, the agent will only be locked into a rally until the first subvaluation is reached. This allows the agent to either withdraw from bidding, or if $D_{6}$ permits, the agent can place another proxy bid at the next subvaluation. The agent can then make a controlled approach towards its true valuation without being caught in a rally with no escape (see Figure $3 \mathbf{E}$ ).

Ultimately, the majority of bids entered will be proxy bids. We define the IsProxy function which uses the following logic to determine if the rival bid is a proxy bid:

1) Determine who is the highest bidder (using $\mathcal{H}$ ).

2) See if other bidders have been competing with this bid.

3) Does this bid have an earlier time stamp than the competing bids?

a) If it has, then it is a proxy bid.

4) In the absence of any competing bids, if the sniper enters a bid and it is immediately outbid by a minimal amount, then it is a proxy bid.

Once it is determined that the rival is a proxy bid, the next significant problem is estimating the magnitude of the proxy bid. That is, the probability of this being a very large bid (high magnitude) or a relatively small bid (low magnitude). The sniper can then base its subvaluations accordingly. There are several factors that influence the calculation of the probability:

1) The number of rival bids made against the proxy bid.

2) The magnitude of the rival bids.

3) If the proxy bidder has made proxy bids in the past, and whether these have been defeated. 

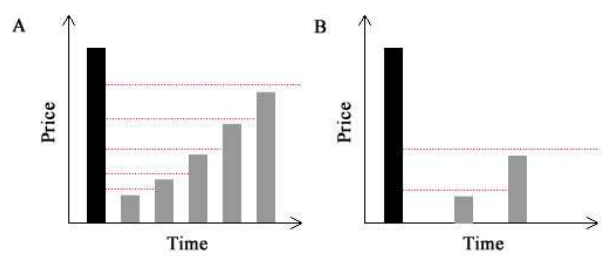

C
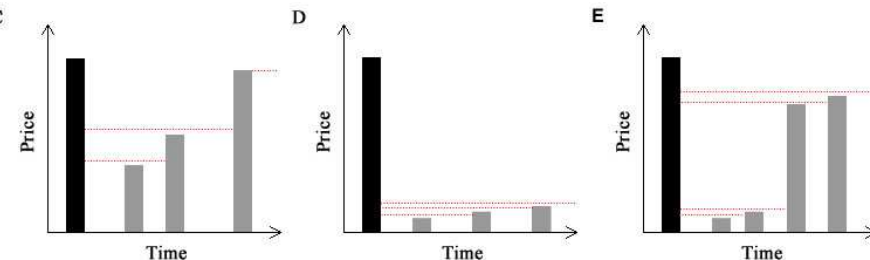

Fig. 4. Different scenarios for determining proxy bid magnitude. A illustrates many competing bids. B shows few competing bids. C depicts the competing bids with high amounts. D shows competing bids for minimal amounts. $\mathbf{E}$ gives an example of competing bids for minimal and high amounts.

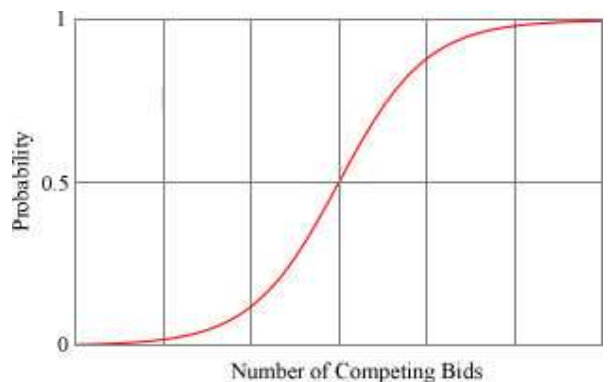

Fig. 5. Curve indicating how the probability of being a high magnitude increases with the number of competing bids.

Figure $4 \mathbf{A}$ and $\mathbf{B}$ illustrate two different scenarios for the number of bidders competing against a proxy bid. In the first instance, there are many competing bids. This would suggest that the proxy bid has a high probability of being of a high magnitude. Whereas in the second scenario there are either no or very few competing bids. This then leans towards the proxy bid having a low probability of being of a high magnitude.

If no competing bids have been made, then the probability $\operatorname{Pr}(A)$, of a proxy bid being competitive is 0 . If competing bids have been made, then we must find a function to determine how $\operatorname{Pr}(A)$ increases with the number of competing bids. Figure 5 illustrates the shape of such a curve. Initially, the probability isn't affected much by one or two competing bids. However, as more competing bids are made, the probability exponentially increases. Once we have a sufficient number of competing bids to indicate that this is a very competitive bid, then the curve levels off with any additional competing bids having little effect on the probability. The probability that there are exactly $k$ bids in interval $t$ is

$$
\operatorname{Pr}(N=k)=\frac{(\lambda t)^{k} \ell^{-\lambda t}}{k !}
$$

The probability that there are $k$ or less bids in interval $t$ is

$$
\operatorname{Pr}(N \leq k)=\sum_{i=0}^{k} \frac{(\lambda t)^{k} \ell^{-\lambda t}}{k !}=\sum_{i=0}^{k} \operatorname{Pr}(N=i)
$$

The probability that there are greater than $k$ bids in interval $t$ is

$$
\begin{aligned}
\operatorname{Pr}(N>k) & =1-\operatorname{Pr}(N \leq k) \\
& =1-\sum_{i=0}^{k} \frac{(\lambda t)^{k} \ell^{-\lambda t}}{k !}
\end{aligned}
$$

Figure $4 \mathbf{C}$ and $\mathbf{D}$ illustrates two different scenarios for amounts bid by bidders competing against a proxy bid. In the first scenario all of the rival bids made are for significantly high amounts (well above the minimum increment). This suggests that there is a high probability that the proxy bid is of a high magnitude. The second scenario has rival bidders only bidding small amounts (at or just above the minimal increment). As such, it is less likely that the proxy bid is of a high magnitude, so the probability is lowered accordingly. The probability $\operatorname{Pr}(B)$, of a proxy bid being of a high magnitude based on the bid increment is calculated as:

$$
\operatorname{Pr}(B)=p / \alpha
$$

The number of competing bids and their amounts can be ignored. We are just interested in what the final competing bid's price $p$ is in relation to the target valuation $\alpha$. If $p$ is high in relation to $\alpha$, then it is likely the the proxy bid is of a high magnitude.

The final factor in determining the sniper's subvaluation strategy is to observe the proxy bidder's bidding history. If the proxy bidder has bid before in the past using either oneoff bids, or previous proxy bids that have been defeated, then it is less likely that the current proxy bid is of a high magnitude. That is, the bidder is likely to continue with the trend of using multiple smaller proxy bids rather than one large one. However, if this is a fresh proxy bid by an unknown bidder, then there is a higher probability that the proxy bid is of a high magnitude. We define $C$ as the number of one-off or defeated proxy bids for proxy bidder.

The probabilities of all three factors can be combined to give an overall probability $\operatorname{Pr}(D)$, that determines the sniper's subvaluation strategy:

$$
\operatorname{Pr}(D)=\frac{\omega_{1} \operatorname{Pr}(A)+\omega_{2} \operatorname{Pr}(B)}{\omega_{1}+\omega_{2}+C}
$$

where $\omega_{2}$ and $\omega_{2}$ are used to weight either characteristic. Depending on the probability of whether or not the proxy bid is of a high magnitude, the next step is to determine how many subvaluations the sniper's valuation should be split into. We use the following approach:

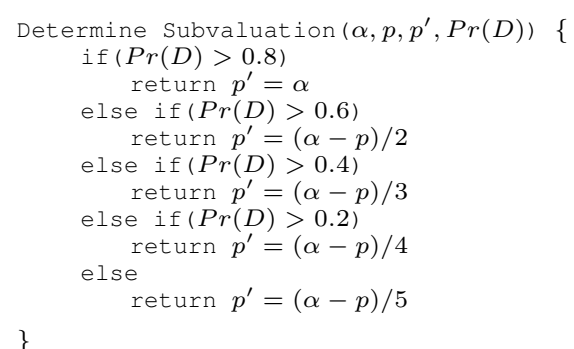

These values are deduced by trial and error. It is up to the user's discretion to change them accordingly. The pseudocode for $D_{7}$ is as follows: 


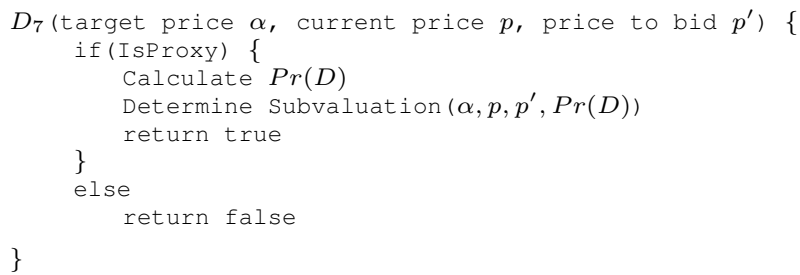

\section{How the Bid Sniping Agent Operates}

The aforementioned directives govern the agent's operation depending on the state of the auction. The following pseudocode illustrates the agent's behaviour:

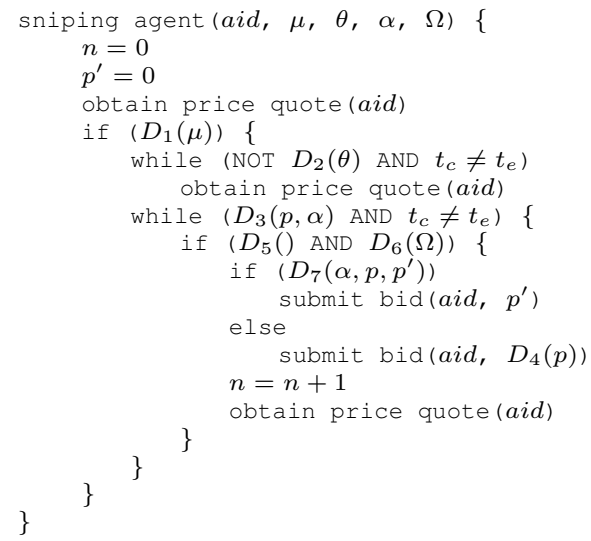

The agent initially requests a price quote. $D_{1}$ determines whether the auction is worth competing in depending on the behaviour of the bidding so far. $D_{2}$ continually checks the auction's time to work out when the agent can commence bidding. Once $t_{S}$ has been reached, $D_{3}$ continually checks to make sure the target price hasn't been exceeded, and the agent also makes sure the auction hasn't terminated. $D_{5}$ and $D_{6}$ respectively determine the timing of a bid and whether to stop if a rally is occurring. If all conditions are satisfied, the agent can submit a bid. $D_{7}$ works out if the rival is a proxy bidder, and if so allows the agent to submit a bid for a subvaluation $p^{\prime}$. If the agent is not up against a proxy bidder, then $D_{4}$ provides the minimal amount that an agent needs to submit for its bid. For every bid submitted, $n$ increases by one. The process continues until either $D_{3}, D_{5}$ or $D_{6}$ return false, or the auction terminates.

\section{Countering Bid SNiping}

This section proposes methods that can be used to proactively discourage bid sniping.

At present, the only preventative measure for a bidder against sniping, is to "out-snipe" the sniper. That is, if one observes a sniper bid, outbid the sniper marginally at a time even closer to the auction's end. However, this is a risky approach, and it all comes down to timing. Effectively, the person with the quicker connection will be the winner.

Employing this strategy often results in there being multiple snipers in an auction. This behaviour leads to failure of the English auctioning process. If everyone engaged in sniping, the auction would essentially become a sealed bid auction [16]. In a sealed bid auction, bidders submit their bids secretly during a bidding round. At the close of bidding, the auctioneer determines the winner. English auctions on the other hand are open bid, and allow bidders to bid multiple times. In a traditional offline English auction, sniping cannot occur. Sniping is a feature unique to online auctions. Sniping behaviour blurs the boundaries of an online auction between the type of auction it is and the rules that govern it.

We propose a new method to prevent bid sniping by using a random time-out period at the end of an auction. The whole problem of bid sniping was introduced as a result of online auctions having a predetermined expiration time. In a traditional (offline) English auction, the auction terminates when no new bids are received after a given time-out. For example, the auctioneer calls "going once", "going twice", and then if no new bids are forthcoming, "sold". If a new bid is made, then the auction continues until the timeout occurs again with no new bids being submitted. Bid sniping is unheard of in this style of auctioning as it essentially cannot occur.

In terms of an online auction, we desire to capture this style of behaviour to deter and effectively render bid sniping ineffective. The new auction mechanism could still terminate at a predetermined time. However, if a new bid is received within the closing seconds, then the auction is automatically extended to give other bidders time to consider the new bid. For example, if a new bid is submitted, the auction may extend by ten minutes beyond the official closing time. The following equation is used to denote this behaviour:

$$
t_{e}=t_{e}+10 \mathrm{mins}
$$

Now let us consider what effect this will have on bid sniping. If a sniper bids, then the auction is extended (say for ten minutes). This gives other bidders time to react. If another bidder does submit a bid, then what options are available to the bid sniper? The sniper could bid straight away. However, this would potentially result in a rally with the regular bidder. Instead, the sniper would most likely wait until the final seconds of the timeout period, but doing so will result in the auction being further extended by ten minutes.

In its simple form, this strategy has largely neutralised the effect of bid sniping. However, it still seems that the sniper's best strategy is to wait until the closing seconds of the extended time-out period. This raises the question, how long can the auction be extended for? If the commodity being sold is of a transient nature (i.e., it is perishable or its value depends on time), then it may be undesirable for the auction to continue on with an indefinite amount of timeout extensions.

To avoid this problem and to further force a bid sniper to behave like a regular bidder, the timeout strategy can be slightly altered in the following manner. Firstly, the auctioneer does not need to announce exactly how long the timeout extension is. This will force the bid sniper to bid sooner, otherwise s/he will risk losing the auction. Secondly, over time the bid sniper will eventually work out exactly how long the time-out extension is through trial and error. To avoid this problem, the auctioneer can make the timeout extension 
random. For example, it may be ten minutes the first time, four minutes the second time, eight minutes the third, etc. If rand () is a function that returns a random number between 0 and 1, then Equation 8 is modified as follows:

$$
t_{e}=t_{e}+(\operatorname{rand}() \times x) \operatorname{mins}
$$

where $x$ is the maximum extension permitted. An unknown randomised time-out extension will essentially spur bid snipers to bid immediately and up to their true valuations. Any delay in submitting their bids might result in the auction terminating and as a result, the sniper misses out on the opportunity to participate. Furthermore, to ensure that an auction doesn't continue indefinitely, an undisclosed random bound on the number of time-out extensions can also be used.

\section{CONCLUSIONS}

This paper investigated the phenomenon of bid sniping and late bidding in commercial online auctions. An analysis of auctions on eBay found that approximately $60 \%$ of auctions had bids that were placed in the final hour prior to closing, and over $30 \%$ had bids that were submitted in the final minute prior to closing. Bid sniping occurs for the following reasons:

1) The existence of an announced auction closing time;

2) The ability to easily suppress the final price through bid sniping;

3) The commonness for an overwhelming number of bidders to engage in bid sniping strategies;

4) The prevalence of shill bidding, and that bid sniping is currently the best defence against shill bidders; and

5) The blatant promotion of bid sniping by commercial bid sniping service vendors.

The main effect is that most auctions degrade into a competition between bid snipers. Buyers who are 'pipped at the post' in the closing seconds are frustrated, and the seller does not gain the full amount of revenue s/he otherwise might have received. Furthermore, the auctioneer may receive less commission if payment is proportional to the selling price.

We presented a software bidding agent that follows a bid sniping strategy. Bid sniping agents are commonly used in commercial online auctions. However, there is little documentation regarding how they actually operate or whether it is in fact ethical to use them. The agent has the ability to suppress an auction's price through knowing when to bid, how much to bid, how to deal with rivals, and when to cease bidding. Future work involves testing the agent in a simulated market place to analyse its ability to suppress the price.

Finally, we discussed approaches to prevent the practice of bid sniping. Obviously bid sniping as a defence against other bid snipers is an inadequate solution. The only real approach is to rethink and alter the format of online auctions to better match that of their offline counterparts. We proposed that an undisclosed random time-out strategy should be used to extend the auction's closing time provided more bids continue to be submitted. This has the effect of forcing everyone to immediately bid their true valuations and gives other bidders time to react to would-be bid snipers. Future work involves fully investigating this style of auction format. Additionally, as much information is undisclosed, there must be a mechanism whereby the auctioneer's actions can be verified after the auction to ensure fairness.

So why does the online auctioning format continue to allow bid sniping? The online auction structure is still relatively new. Commercial online auctioneers appear to be happy with the existing structure and are perhaps unwilling to alter things through fear of affecting the company's profitability. In a traditional auction the auctioneer has to provide a fair and level playing field for the bidders. But the distinction of what is equitable is becoming lost in the online environment. The presence of snipers forces the auction to become more of a sealed-bid format rather than open-bid style auction. As such, a novice bidder doesn't understand the rules and is unaware of the strategies for a sealed bid auction. However, snipers do understand the strategies, and use the system at the expense of the novice bidders and sellers. Until the situation is rectified, online auctions will suffer as an exchange mechanism. This is an untenable position that is ultimately detrimental to auction participants and the economy as a whole.

\section{REFERENCES}

[1] Bapna, R., When snipers become predators: can mechanism design save online auctions? Communications of the ACM, Volume 46, Issue 12 , pp. 152-158, 2003.

[2] Dumas, M., Aldred, L. and Governatori, G., A probabilistic approach to automated bidding in alternative auctions, In Proceedings of the eleventh international conference on World Wide Web, pp. 99-108, 2002.

[3] Engelberg, J., Williams, J., eBay's proxy bidding: A license to shill, Journal of Economic Behavior and Organization, 72 (1), pp. 509-526, 2009.

[4] Gjerstad, S. and Dickhaut, J., Price formation in double auctions, Games and Economic Behavior, 22, pp. 1-29, 1998.

[5] Lee, H.M., Wang, C.W. and Su, J.S., Applying self-organization map to prevent the shill bidding in online auctions, International Journal of Innovative Computing, Information and Control, 6 (3), pp. 1141-1150, 2010.

[6] Leonardo, R., Ruy, G., Safe reverse auctions protocol - Adding treatment against collusive shill bidding and sniping attacks, In Proceedings of ICETE 2009 - International Joint Conference on e-Business and Telecommunications, pp. 239-244, 2009.

[7] Marcoux, A.M., Snipers, Stalkers, and Nibblers: Online Auction Business Ethics, Journal of Business Ethics 46 (2), pp. 163-173, 2003.

[8] McAdams, D. and Schwarz, M., Who pays when auction rules are bent? International Journal of Industrial Organization, 25 (5), pp. 1144-1157, 2007.

[9] Roth, A. and Ockenfels, A., Last-Minute Bidding and the Rules for Ending Second-Price Auctions: Evidence from eBay and Amazon Auctions, The American Economic Review, Vol. 92, No. 4, pp. 1093-1103, 2002.

[10] Rust, J., Miller, J. and Palmer, R., Behaviour of trading automata in a computerized double auction market, In The Double Auction Market: Institutions, Theories, and Evidence. Addison-Wesley, 1992.

[11] Schwartz, J. and Dobrzynski, J., 3 men are charged with fraud in 1,100 art auctions on eBay, The New York Times, 2002.

[12] Shah, H., Joshi, N. and Wurman, P., Mining for bidding strategies on eBay, In SIGKDD'2002 Workshop on Web Mining for Usage Patterns and User Profiles. 2002.

[13] Trevathan, J. and Read, W., - Shilled - Fraud and security in online auctions, VDM-Verlag, Germany, 168 pages, 2008.

[14] Trevathan, J. and Read, W., Detecting Shill Bidding in Online English Auctions, Handbook of Research on Social and Organizational Liabilities in Information Security, (Manish Gupta and Raj Sharman eds.), IGI Press, Chapter 27, pp. 446-470, 2008.

[15] Vergano, D., On eBay, It Pays to Snipe, USAToday, 2006.

[16] Vickrey, W., Counter Speculation, Auctions and Competitive Sealed Tenders, Journal of Finance, 16, pp. 8-37, 1961. 